Original Research

\title{
Research on the Treatment of Municipal Solid Waste Source Classification Behavior Based on Institutional Engineering - Comment on "Shanghai Municipal Domestic Waste Management Regulations"
}

\author{
Xiaofeng Weng* \\ Business School, University of Shanghai for Science and Technology, Shanghai 200093, China
}

Received: 9 January 2021

Accepted: 23 June 2021

\begin{abstract}
Currently, waste classification management is being carried out in various parts of China. In order to solve the pain points and difficulties of individuals" "reluctant to sort, lazy to sort", which is the source of domestic waste management behavior, the thesis is based on the cost-utility theory, using institutional engineering research methods to study the behavioral cost and utility of individuals' disposal of domestic waste. Studies show that after the implementation of waste classification management, the increase in the cost and the decline in utility of the individuals' behaviors in handling domestic waste is the root cause of the failure of waste classification management in China. At present, the implementation of Shanghai's domestic waste management regulations has problems such as mismatch of penalties, poorly targeted penalties, excessive supervision costs, too few convenient facilities, and individuals' resistance. The paper puts forward a "double-track" differentiated garbage classification management method, in which market mechanism is introduced to collect garbage classification service fee from individuals with time cost and reward individuals without time cost, while existing measures such as strengthening supervision and increasing convenient garbage classification facilities are taken. On the premise of ensuring the implementation of waste classification management objectives, the utility of individuals' waste classification behavior can be improved, the government supervision cost can be reduced, and the Pareto improvement can be achieved.
\end{abstract}

Keywords: household garbage, garbage classification, double track, garbage classification utility

*e-mail: 181910096@st.usst.edu.cn 


\section{Introduction}

As China's urbanization rate continues to increase and people' consumption capacity continues to grow, the domestic waste generated by urban persons has risen rapidly [1]. Which has attracted the attention of many local government leaders and scholars [2]. In order to create a good living environment, reduce garbage hazards, and eliminate waste of resources, major cities in China have experienced many garbage sorting campaigns. As early as July 12, 1957, the Beijing Daily published an article on the headline of the front page of "Garbage should be collected separately", and proposed to carry out the source classification management of urban domestic garbage [3]. In 1996, Beijing implemented a two-barrel garbage classification management system of "recyclable garbage" and "nonrecyclable garbage". Since 2000, 8 cities including Beijing, Shanghai, Guangzhou, Nanjing, Shenzhen, Hangzhou, Xiamen, and Guilin have successively carried out the management of waste classification [4]. In 2012, Beijing began to implement the "Beijing Municipal Domestic Waste Management Regulations". In March 2017, the National Development and Reform Commission and the Ministry of Housing and UrbanRural Development issued the "Implementation Plan for the Domestic Waste Classification Regulations", requiring 46 key cities, including Shanghai, to implement mandatory domestic waste classification management regulations $[5,6]$. From the perspective of management effectiveness, the domestic waste classification management implemented many times in the past ended in failure. From July 1, 2019, Shanghai has taken the lead in implementing a new waste sorting policy. In this process, there is still room for improvement in the participation rate of household garbage classification, and the classification and treatment of garbage at the source has a long way to go [7].

Municipal solid waste classification management is a systematic project. There are many reasons for the failure of solid waste classification management. The key reason is that the core problem of individuals "do not want to sort, lazy to sort" [8] has not been solved well, and then a scientific and effective governance plan has not been formulated. Therefore, it is necessary to discuss the issue of waste classification management from the perspective of personal waste disposal behavior.

\section{Literature Review and Comment}

\section{Literature Review}

European and American countries implemented waste classification management policies early, and there are many research results on the source classification behavior of municipal solid waste. Judging from the existing research results, there are mainly six theories in behavioral research involving garbage classification, including value theory [9], environmental cognition theory [10], comfort preference theory [11], 12], utility perception theory [13], group norm theory [14, 15], and social capital theory [16]. The value theory believes that, compared to people with individualistic and selfcentered values, people who uphold social altruistic values and surpass self-values are more willing to give up their personal interests and engage in behaviors that are beneficial to the environment and others [17-21]. A person's ecological values have a significant effect on reducing the amount of household garbage, promoting garbage recycling, and improving garbage recycling [22-24]. The theory of environmental cognition believes that the more people have knowledge of garbage classification, the more they will actively participate in related regulations of garbage classification and garbage recycling activities [25-27], there is an obvious causal relationship of them [28]. Through the investigation of college students, Zhang et al. [25] found that the more college students understand the hazards of garbage pollution, the more they understand the role of garbage classification, and the more they can accept garbage classification management policies. However, some scholars have found through research that there is no obvious causal relationship and correlation between cognition and garbage classification behavior [29-31], or the correlation is very low [32-35]. The comfort preference theory believes that people's decision on whether to implement garbage classification regulations depends to a large extent on people's comfort level in the process of garbage classification. When faced with whether to dispose of garbage according to the garbage classification regulations, people will choose behaviors that are not expensive and do not require much effort. Garbage sorting and recycling facilities that are convenient, large in quantity, and able to reduce the time for sorting garbage have a significant impact on individuals' garbage sorting and disposal behavior. Local governments provide convenient garbage sorting facilities and services, and individuals' willingness to participate in household food waste sorting will increase [36]. The convenient public facilities for garbage sorting can motivate individuals to choose garbage sorting more than preaching or written explanations about garbage sorting. Whether it is waste sorting or green ecological housing, whether people feel comfortable is an important basis for which behavior strategy people adopt. If a person feels that the garbage sorting behavior makes them feel happy, they will sort the garbage spontaneously. Conversely, if a person perceives that the garbage sorting behavior will bring discomfort to their lives, they are more inclined not to sort the garbage [37, 38]. Studies have shown that the conclusions of comfort preference theory and the conclusions of values theory may be opposite [39]. The theory of utility perception believes that the most important determinant of whether garbage sorting behavior can be generated is the personal reward and loss and convenience that people feel in garbage sorting activities [40]. Reducing 
the cost of sorting garbage can stimulate people's waste sorting behavior [41]. Whether people can obtain utility from garbage classification, and the low cost, easy operation, and convenience determines whether people will classify garbage [42]. The theory of group norms believes that the norms of group ethics have a significant impact on whether individuals follow the garbage classification regulations to dispose of garbage [43]. The ethics formed by groups closely related to individuals play a key role in the classification and disposal of "kitchen waste" by individuals [44]. If friends actively participate in garbage sorting, personal participation in garbage sorting activities will also be very active. In Shanghai, it may appear that I am a Shanghainese, and I cannot lose the face of Shanghainese. The theory of social capital believes that social capital can have a significant positive impact on the classification of domestic waste [45]. Cultivating social capital to form an independent governance model has become a new direction for improving the effectiveness of domestic waste governance [46], and a community should create an opportunity for the residents to communicate, consolidate and improve their trust bond with one another [47]. In addition to the above theories, the use of statistics to study garbage classification behavior has also yielded many inspiring results. For example, there are more women than men who carry out garbage sorting activities [48], they are economically affluent and have higher education, and well-educated elderly people are the most active in participating in garbage sorting activities [49]. However, some scholars have found that individuals with low income levels are positively related to environmental protection behaviors [50], households with large populations are more willing to follow the rules of garbage sorting behavior than households with small populations [51]. Households with smaller houses are more likely to engage in garbage sorting activities than individuals with larger houses [52].

\section{Literature Comment}

The above scholars study the attitudes and motivations of individuals in the classification behavior of domestic waste, which have a certain theoretical guidance role for the further research of the classification behavior of domestic waste. Among them, the theory of utility perception that the premise of effective garbage classification behavior is to reduce losses and obtain rewards is consistent with this paper's research entry point, the comfort preference theory is similar to the viewpoint of this article, but the research methods, research process and policy recommendations are different. Excluding these scholars, others have the following problems in their research: First, they have not fully considered the basic fact that the sense of rational people plays a leading role in the process of garbage classification. Especially value theory, environmental cognition theory and group norm research theory, seem to completely ignore this point.
Second, they are lack of professional system design theories and methods, and corresponding behavioral conceptual models and mathematical models have not been constructed. Most studies use social surveys and statistics to infer that a certain factor has a causal or correlation relationship with the garbage classification of individuals, without fully considering the driving force and restraint of human behavior, and lack of research on how various factors interactively drive the behavior of urban individuals' garbage classification, ignorance and not grasp that the driving mechanism of behavior is a prerequisite for effective intervention in garbage classification behavior, which lead to the practicability of research results to be discussed. Third, there is a lack of effective policy response. The goal of the policy formulation of garbage sorting behavior is to regulate individuals' garbage sorting behavior while not reducing the effectiveness of individuals' handling of domestic garbage and not increasing management costs. In the process of formulating and implementing a standardized waste sorting management system, ignoring the attitudes and reactions of individuals will not only deviate from the original intention of policy formulation, but may also cause policy backlash. The failures of the past few waste sorting management systems are a precedent. Therefore, it is also important to discuss the attitude and response of policy executors (urban individuals) to the domestic waste classification and guidance policy and management costs.

The innovation or contribution of this article lies in four aspects. First, this article introduces the research method of institutional engineering for the first time in the research process. Garbage classification management is essentially the comparison and selection of management mechanisms, which belongs to the category of institutional design and evaluation. Second, although the cost-benefit theory is not new, but in the known waste classification management research, this article applies cost-utility theory to this field for the first time in China. Third, from a realistic point of view, this article divides the behavior subjects of garbage disposal into two types of behavior subjects: individuals with no time cost and individuals with time cost. This classification is the first time in existing garbage classification research. Fourth, in addition to discovering that the current waste management regulations need to be improved, this article also proposes a "dual-track" waste classification management method, which is the first time in existing research.

\section{Analysis and Model Construction of Source Classification Behavior of Municipal Solid Waste}

\section{Theoretical Basis and Research Methods}

Cost-utility theory refers to the behavioral subject as a rational person who makes decisions based on 
the principles of loss, lowest cost, highest profit, and maximum utility when faced with multiple possible behavioral decisions. Individuals disposal of garbage includes identification, sorting, packaging, transportation, and delivery. These behaviors consume physical strength and waste time, which is a burden and can be regarded as a cost. Individuals dispose of the garbage to avoid the smell of garbage, eliminate air pollution, release the house space, and improve the living environment, which can be regarded as a benefit. Under normal circumstances, individuals will choose the behavior of garbage disposal, which indicates that the benefits of garbage disposal are higher than the cost of behavior. Otherwise, people will not choose garbage disposal behavior, that is, the effectiveness of the behavior of individuals' garbage disposal is positive. When individuals handle garbage, the cost of mixed garbage behavior is low, and the cost of garbage sorting behavior is high. Under the condition of equal benefits, the utility of mixed garbage behavior is higher than that of garbage sorting behavior. This can well explain that without external intervention, individuals would choose to mix garbage instead of sorting and disposing of garbage. Therefore, it is appropriate to apply the cost-utility theory to the study of garbage classification behavior.

This paper adopts the method of institutional engineering to analyze the individuals' behavior in handling garbage, constructs conceptual models and mathematical models, and proposes policy recommendations. Institutional engineering was founded by Professor Sun Shaorong [53]. It is a scientific research method of broad institutional design that studies the behavior of people and organizations. This research method has three steps: firstly, describe the behavior of people or organizations, then use methods similar to designing circuit diagrams and mechanical diagrams to construct behavioral conceptual models using different shapes of graphic symbols. Finally, a mathematical model is established and calculated, so as to obtain the internal laws of human or organizational behavior, and provide decision-making suggestions for management systems including policies and regulations, codes of conduct, and codes of conduct.

Models of Individuals' Garbage Disposal Behavior before Implementation of Garbage Classification Management Regulations

\section{Analysis and Conceptual Model of Individuals' Garbage Disposal Behavior before Implementing Regulations on Garbage Classification Management}

Individuals' garbage disposal behavior has rational characteristics, focusing on behavioral costs, behavioral benefits, and behavioral utility. The physical and mental energy spent in garbage disposal is the behavior inhibitor of garbage disposal, which inhibits garbage disposal. Treating garbage to make the house clean is

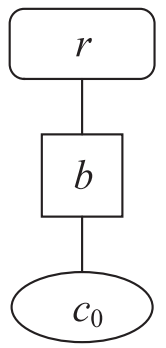

Fig. 1. Conceptual model of individuals' handling of mixed waste before implementing waste sorting management.

the promoter of garbage disposal behavior and promotes the behavior of garbage disposal. Fig. 1 is a conceptual model of individuals' garbage disposal behavior before implementing garbage classification management.

In Fig. 1: $b$ - individuals' behavior of handling mixed garbage, represented by squares; $r$ - individuals' behavioral benefits of handling mixed garbage, represented by rounded rectangles; $c_{0}$ - individuals' behavioral costs of handling mixed garbage, represented by ellipses.

\section{Mathematical Model of Individuals'Treatment of Mixed Waste before Implementation of Waste Classification Management Regulations}

Assuming that individuals are completely rational people, the utility function for individuals to dispose of mixed waste is:

$$
u=r-c_{0}
$$

In the above formula, $r$ : the income of individuals throwing mixed garbage, $r>0 ; c_{0}$ : the cost of individuals throwing mixed garbage, $c_{0}>0 ; u$ : the utility of individuals disposing of mixed garbage, $u>0, r_{0}>c_{0}$.

\section{Individuals' Behavior Model of Garbage Disposal According to the Regulations of Garbage Classification Management}

\section{The Behavior Analysis and Conceptual Model of the Individuals who Implement The Garbage Classification Management Regulations}

Since Shanghai implemented the "Regulations of Shanghai Municipality on the Management of Domestic Waste", inspectors have been arranged from time to time in places where individuals throw garbage. These inspectors inspect, guide, educate and even punish the behavior of randomly disposing of garbage that does not follow the classification regulations, playing the role of "police". The act of sorting and disposing of garbage consumes more physical strength, energy and time of individuals, thus increasing the cost of individuals disposing of garbage. At this time, the income of 
individual remains unchanged and still exceeds the cost. Individuals will dispose of rubbish as required when they are supervised by the "police". Individuals will be lazy when the "police" is not supervised and may choose the behavioral strategy of throwing mixed rubbish, but if discovered by the "police", they will be required to pay a fine or other punishment. At this time, the "policeman" belongs to the monitor and plays a monitoring role.

When the individuals strictly follow the current garbage classification regulations, he or she increases the labor of garbage classification, which increases the labor link of garbage classification compared with the previous behavior of throwing mixed garbage, which means that the physical labor, energy and time cost are increased, and no benefits occur variety.

Observations in real life have found that from the perspective of time cost, the individuals who handle garbage can be divided into two types: individuals with no time cost and individuals with time cost.

(1) Analysis and conceptual model of garbage classification behavior of individuals without time cost.

Individuals with no time cost are also called individuals with no opportunity cost, which refer to individuals who have not lost other benefits when implementing garbage classification. In order to clarify the behavioral characteristics of different time costs more clearly, this article refers to individuals who have no time cost at all and those with very low time costs collectively as individuals with no time cost. Under normal circumstances, low-income groups, retired elderly, unemployed, etc. are individuals with no time costs. This group of people has low opportunity cost and relatively ample time. They are less disgusted or even resistant to garbage sorting (increasing costs) according to regulations. When dealing with garbage according to the garbage classification regulations, they may follow the regulations to sort the garbage and then dispose of the garbage, or they may not dispose of the garbage in accordance with the regulations, but treat the mixed garbage as before. Due to the existence of the "police" and the uncertainty of the supervision of the "police", it is difficult to fully supervise one hundred percent. Therefore, individuals may be caught by the "police" when they choose to deal with mixed garbage. When not caught by the police, the cost for individuals to dispose of garbage is the same as that of mixed garbage before, but being caught by the "police" will not only increase the cost of sorting garbage, but also increase the cost of punishment. Fig. 2a) is a conceptual model of the behavior of individuals with no time cost in disposing of garbage according to the requirements of garbage classification, and Fig. 2b) is a conceptual model of the behavior of individuals who do not handle garbage according to garbage classification requirements without time cost.

In Fig. 2a) $b_{1}$ : the behavior of individuals without time cost to dispose of garbage according to garbage classification regulations; $c_{0}$ : the behavioral cost of individuals with no time cost to dispose of mixed waste; $c_{1}$ : the behavioral cost added by individuals with no time cost on the basis of handling mixed waste, including the cost of identifying, sorting, and putting garbage; $r_{1}$ : the income of individuals who have no time cost from disposing of garbage according to garbage classification regulations.

In Fig. 2b) $b_{21}$ : the garbage disposal behavior in which individuals who have no time cost do not dispose of garbage according to garbage classification regulations and are not caught; $b_{22}$ : the garbage disposal behavior of individuals who do not follow the garbage classification regulations and are caught without time $\operatorname{cost} ; c_{0}$ : the behavioral cost of individuals with no time cost to dispose of mixed garbage; $c_{1}$ : the extra behavioral cost of the individuals who has no time cost and fail to dispose of the garbage according to the regulations, and are caught after processing the mixed garbage, that is, the cost of identifying, sorting, and putting garbage; $r_{2}$ : the income of individuals who have no time cost for not disposing of garbage as required and not being caught by the "police"; $r_{3}$ : the income of a)

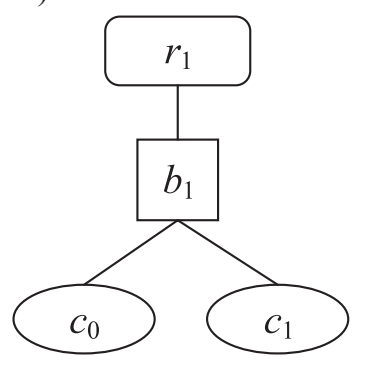

b)

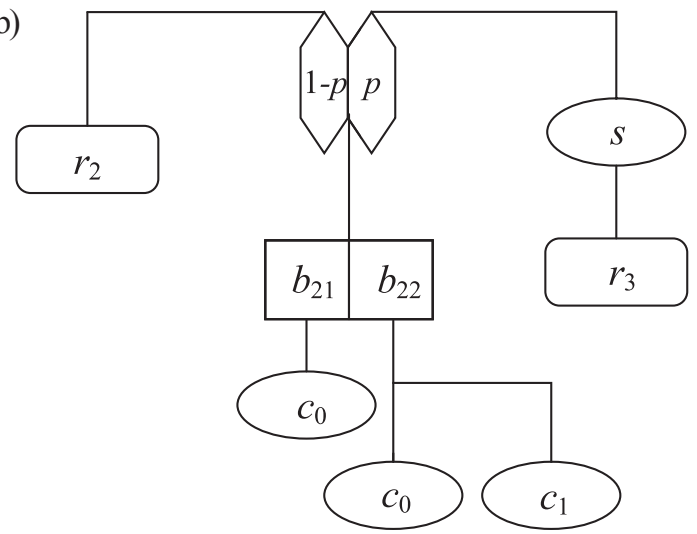

Fig. 2. a) conceptual model of the behavior of individuals with no time cost in handling garbage according to garbage classification regulations; b) conceptual model of the behavior of individuals who do not follow the garbage classification regulations to dispose of garbage without time cost. 
individuals who have no time cost and are caught by the "police" who fail to dispose of garbage as required; $s$ : the punishment for individuals who have no time cost and are caught by the "police" who fail to dispose of garbage according to regulations; $p$ : the probability that individuals with no time cost will be caught when he or she does not dispose of garbage according to the classification regulations under the supervision of "police"; 1- $p$ : the probability that an individuals who have no time cost will not be caught by the "police" who does not handle garbage according to the classification regulations when there is a "police" supervision.

(2) Analysis and conceptual model of garbage classification behavior of individuals with time cost.

Individuals with time costs is also called opportunity-cost individuals, which refer to individuals who have lost other benefits due to the practice of sorting garbage. For the convenience of research, this article refers to individuals with higher time costs as individuals with time costs. People with high incomes and a lot of work are generally individuals with time costs. This group of people is short on time and has high opportunity costs. They are highly resistant to garbage sorting according to regulations. In addition, the penalty amount accounts for a low proportion of their income. Compared with individuals who have no time cost, he or she is more inclined to take the risk of disposing of mixed garbage. There are also two possibilities for this group of people to dispose of classified garbage according to regulations and dispose of mixed garbage not according to regulations. They may also be caught or escaped when garbage is not handled according to regulations. Fig. 2c) and Fig. 2d) are the behavioral conceptual models of individuals who have time costs to dispose of garbage according to garbage classification regulations and not to dispose of garbage according to classification requirements.

In Fig. 2c) $b_{1}$ : individuals who have time costs handle garbage according to garbage classification regulations; $c_{0}$ : the behavioral cost of individuals who have time cost to dispose of mixed garbage; $c_{1}$ : the extra behavioral cost of individuals who have time cost to dispose of mixed garbage, that is, the cost of sorting garbage; opp: the opportunity cost of the individuals with time cost when sorting garbage; $r_{1}$ : the income of individuals who have time cost to dispose of garbage according to garbage classification regulations.

In Fig. 2d) $b_{21}$ : the garbage disposal behavior in which individuals who have time cost do not handle garbage according to garbage classification regulations and are not caught; $b_{22}$ : the garbage disposal behavior in which individuals have time cost and are caught who do not handle garbage according to garbage classification regulations; $c_{0}$ : the behavioral cost of individuals with time cost to dispose of mixed garbage; $c_{1}$ : the extra behavioral cost added to the treatment of mixed garbage after the individuals with time cost are caught, that is, the cost of identifying, sorting, and putting garbage; opp: the increased time cost for individuals who have time cost to process classified garbage according to regulations; $r_{2}$ : the income of individuals who have time costs for not disposing of garbage according to regulations and not being caught by the "police"; $r_{3}$ : the income of individuals who have time cost and are caught by the "police" who fail to dispose of garbage according to regulations; $s$ : the punishment for individuals who have time cost and is caught by the "police" who fail to dispose of garbage according to regulations; $p$ : the probability that individuals who have time cost will be caught if he or she does not handle garbage according to the classification regulations when there are "police"; $1-p$ : the probability that individuals with time cost will not be caught if they do not dispose of garbage according to the classification requirements when there are "police".

\section{Mathematical Model of Individuals' Garbage Disposal Behavior when Implementing Garbage Classification Management Regulations}

At present, Shanghai implements a nondiscriminatory policy for the management of c)

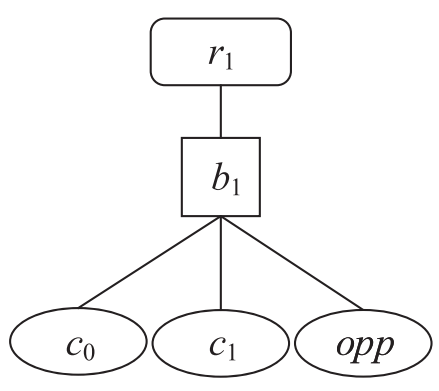

d)

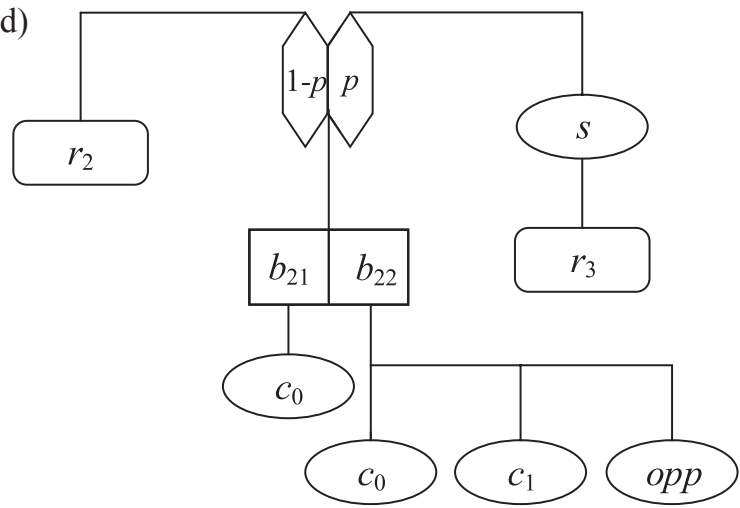

Fig. 2. c) conceptual model of the behavior of individuals who have time cost to deal with garbage according to garbage classification regulations; d) conceptual model of the behavior of individuals with time cost not disposing of garbage according to garbage classification regulations. 
individuals' garbage disposal in violation of regulations. All individuals, including individuals with no time cost and individuals with time cost, implement the same management system with "police" and not all-weather monitoring. The mathematical model and influence of this management system are as follows:

(1) Mathematical model of garbage disposal behavior of individuals without time cost

- The utility function of individuals without time cost when disposing of garbage according to the regulations of garbage classification is:

$$
u_{1}=r_{1}-c_{0}-c_{1}
$$

In the formula, $c_{0}$ : the behavioral cost of mixed waste disposal; $c_{1}$ : according to the garbage classification requirements, the additional garbage classification cost based on the original mixed treatment of garbage; $r_{1}$ : benefits from the cleanliness of garbage disposal, $r_{1}=r, r_{1}>c_{0}+c_{1}$, otherwise, individuals will not choose the behavioral strategy of garbage disposal; $u_{1}$ : the utility that individuals without time cost obtain when he or she disposes of garbage according to garbage classification regulations, $u_{1}>0$.

- The expected utility of individuals without time cost when he or she do not treat garbage according to the garbage classification regulations is:

$$
u_{2}=\left(1-p_{1}\right)\left(r_{2}-c_{0}\right)+p_{1}\left(r_{3}-s_{1}-c_{0}-c_{1}\right)
$$

In the formula, $s_{1}$ : punishment for those who are not following the garbage classification regulations after being caught; $r_{2}$ : profit after not being caught by the "police", $r_{2}=r_{1}=r ; r_{3}$ : profits after being caught by the "police", $r_{3}=r_{2}=r_{1}=r ; u_{2}$ : expected utility when individuals with no time cost do not dispose of garbage according to garbage classification regulations, $u_{2}>0 ; p_{1}$ : the probability of being caught if you don't follow the regulations; $1-p_{1}$ : the probability of not being caught by throwing away garbage in violation of regulations.

The conditions for the effective classification of waste management system are:

$$
u_{1}>u_{2}
$$

That is:

$$
\begin{aligned}
& r_{1}-c_{0}-c_{1}>\left(1-p_{1}\right)\left(r_{2}-c_{0}\right)+p_{1}\left(r_{3}-s_{1}-c_{0}-c_{1}\right) \\
& \text { In addition } r_{1}=r_{2}=r_{3}=r .
\end{aligned}
$$

Therefore, effective punishment $s_{1}{ }^{*}$ can be obtained:

$$
s_{1}^{*}>\frac{\left(1-p_{1}\right) c_{1}}{p_{1}}
$$

Effective supervision probability $p_{1}^{*}$ :

$$
p_{1}^{*}>\frac{c_{1}}{c_{1}+s_{1}}
$$

The above analysis shows that for the current garbage classification management system in Shanghai, for individuals with no time cost, the prerequisite for the system to be effective is that the punishment is greater than $\left(1-p_{1}\right) c_{1} / p_{1}$ or the probability of catching individuals with no time cost not handling garbage as required is greater than $c_{1} /\left(c_{1}+s_{1}\right)$. In other words, in order for individuals to strictly follow the garbage classification regulations to dispose of garbage, the "policeman" must implement effective punitive measures or exercise effective supervision on individuals who fail to dispose of garbage as required.

(2) Mathematical model of garbage disposal behavior of individuals with time cost.

- The utility function of individuals with time cost when disposing of garbage according to the garbage classification regulations is:

$$
u_{1}^{\prime}=r_{1}-c_{0}-c_{1}-o p p
$$

In the formula, opp: opportunity costs for individuals with time costs to dispose of garbage according to garbage classification regulations; $u_{1}^{\prime}$ : the utility that individuals who have time costs get when they dispose of garbage according to garbage classification regulations.

- The expected utility $u_{2}{ }^{\prime}$ of individuals who have time cost when he or she does not dispose of garbage according to the garbage classification regulations are:

$$
u_{2}^{\prime}=\left(1-p_{2}\right)\left(r_{2}-c_{0}\right)+p_{2}\left(r_{3}-c_{0}-c_{1}-o p p-s_{2}\right)
$$

The conditions for the effective classification of waste management system is:

$$
u_{1}^{\prime}>u_{2}^{\prime}
$$

That is:

$r_{1}-c_{0}-c_{1}-o p p>\left(1-p_{2}\right)\left(r_{2}-c_{0}\right)+p_{2}\left(r_{3}-c_{0}-c_{1}-o p p-s_{2}\right)$

In addition $r_{1}=r_{2}=r_{3}=r$.

Therefore, the following effective punishment $s_{2}{ }^{\prime}$ can be obtained:

$$
s_{2}^{*}>\frac{\left(1-p_{2}\right)\left(c_{1}+o p p\right)}{p_{2}}
$$

Effective supervision probability $p_{2}{ }^{\prime}$ : 


$$
p_{2}^{*}>\frac{c_{1}+o p p}{c_{1}+o p p+s_{2}}
$$

The above analysis shows that the current garbage classification management system for individuals with time cost, the prerequisite for the system to be effective is that the punishment is greater than $\left(1-p_{2}\right)\left(c_{1}+o p p\right) / p_{2}$ or the probability of catching individuals with time cost not handling garbage as required is greater than $\left(c_{1}+o p p\right) /\left(c_{1}+o p p+s_{2}\right)$.

\section{Discussion}

\section{Policy Evaluation of Shanghai Waste Sorting Management System}

\section{The Cost of Supervision is too High, and the Punishment is Mismatched}

Comparing the effective punishment intensity and effective supervision probability (5)(6)(10)(11) of individuals with no time cost and individuals with time cost, we can find the requirements for punishment and effective supervision probability for individuals with time cost and those without time cost are different. Under the premise of ensuring the effective implementation of the garbage classification management system, there are higher requirements for the punishment and the probability of effective supervision for individuals who have time costs for not handling garbage as required. In order to ensure the effective implementation of the garbage classification management system, there are two system design schemes: The first scheme is to implement different punishment policies for individuals with different time costs. The advantage of this strategy is accuracy, but the disadvantage is poor operability, and it is impossible to confirm which individuals have low time costs and which individuals have high time costs. The second scheme is to implement uniform punishment and supervision probability for all individuals. The second plan is currently implemented in Shanghai. The advantage of this management system is that there is no need to distinguish the time cost attributes of individuals, and it is highly maneuverable.

According to the survey, Shanghai has arranged supervisors at all domestic rubbish stations $(21,000)$, and the implementation of the non-discriminatory garbage classification management method, with an effective supervision rate of $100 \%$. Supervision expenditures for supervisors in the name of volunteers are $1,800 \mathrm{CNY} /$ month. In order to ensure the effective implementation of waste classification management regulations, Shanghai has paid 37.8 million $\mathrm{CNY}$ /month and 453.6 million CNY/year for supervision. This highinput, high-cost waste sorting management method is unbearable for other cities with low fiscal revenues in China.

Currently, the minimum wage in Shanghai is 22 $\mathrm{CNY} /$ hour (excluding social insurance premiums paid by individuals and units according to law), individuals' garbage sorting time is calculated as 1 minute, and the lowest cost of local individuals' garbage sorting is $0.37 \mathrm{CNY}$. Assuming that the effective supervision probability is greater than or equal to 0 and less than or equal to 1 , perform data analysis on (5) (6) (10) (11), as shown in Fig. 3.

Fig. 3a) shows the relationship between effective supervision rate and fine amount for individuals without time cost. According to the model, the effective supervision probability is $100 \%$, that is, under the current management mode (37.8 million $\mathrm{CNY} /$ month supervision fee), the lower limit of the fine is 0.0037 $\mathrm{CNY}$. If the effective supervision rate is reduced to $1 \%$, that is, when the supervision fee is $37,800 \mathrm{CNY}$ /month, the corresponding fine is $370 \mathrm{CNY}$. In other words, the fine amount is more than $370 \mathrm{CNY}$, and the city's management fee is $37,800 \mathrm{CNY} /$ month, which can effectively supervise the waste classification of individuals without time cost. Fig. 3b) is a diagram of the relationship between the effective supervision rate implemented for individuals with time costs and the amount of fines. Taking the time cost opp $=0.51$ $\mathrm{CNY}$ as an example (calculated based on the median income of individuals in Shanghai in 2020 of 6,378 $\mathrm{CNY} /$ month), the effective supervision rate is $100 \%$,
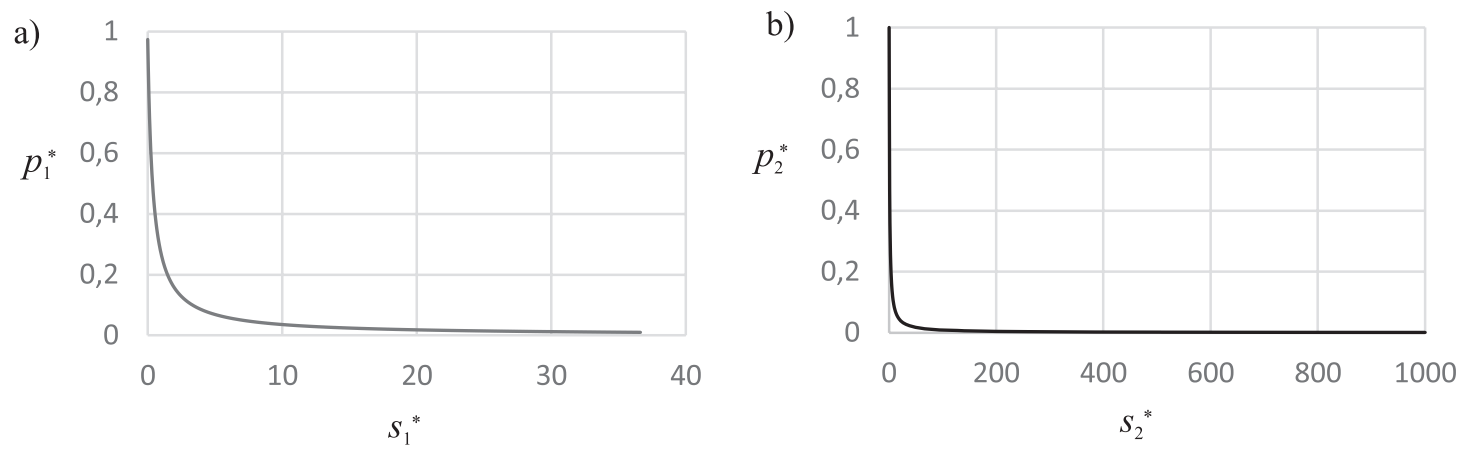

Fig. 3. a) Fines and effective supervision rate for individuals without time cost; b) Fines and effective supervision rate for individuals with time costs (median income). 
Table 1. Violation fines and supervision costs for individuals with no time cost and individuals with time cost under effective supervision.

\begin{tabular}{|c|c|c|}
\hline & $100 \%$ supervision rate & $1 \%$ supervision rate \\
\hline Supervision fees & $¥ 37.8$ million /month & $¥ 37,800 /$ month \\
\hline $\begin{array}{c}\text { Fine requirements for individuals with no time cost } \\
\text { Fine requirements for individuals who have time costs } \\
\text { (Median income individuals) }\end{array}$ & $¥ 0.0037$ & $¥ 880$ \\
\hline Current fine requirements in Shanghai & $¥ 50-200$ & $/$ \\
\hline
\end{tabular}

Note: The time cost of individuals with time costs is based on the median income of Shanghai individuals in 2020.

that is, under the current management measures, the lower limit of the fine is $0.51 \mathrm{CNY}$. If the effective supervision rate is reduced to $1 \%$ and the management fee is $37,800 \mathrm{CNY} /$ month, the corresponding fine is 880 CNY. In other words, when the fine is more than 880 $\mathrm{CNY}$ and the supervision fee is $37,800 \mathrm{CNY} /$ month, the time cost is $0.51 \mathrm{CNY}$, and the garbage classification behavior of individuals who are in the median income and has time cost can be effectively treated. According to model calculations, the current fine amount far exceeds actual needs when the effective supervision rate is $100 \%$. The fine amount of $50-200$ $\mathrm{CNY}$ is in vain and the supervision cost is extremely high. Table 1 is a comparison chart of the amount of fines and supervision fees for effective management of waste classification.

In addition, judging from the management measures of Article 54 and 57 of the "Regulations of Shanghai Municipality on the Management of Domestic Waste" currently being implemented in Shanghai, the punishment for individuals who violate the regulations on garbage classification and disposal of garbage is 50-200 CNY. Those who cause bad consequences will also be included in the list of untrustworthy, and personal information will be collected on the credit information platform. The two penalties of fines and inclusion on the untrustworthy list in the "Regulations" are not implemented concurrently. Instead, fines will be imposed on those who violate the rules and those who have caused serious consequences will be included in the list of dishonesty. For individuals with no time cost, their income is lower, and the penalty amount stipulated in the "Regulations" is effective under the current $100 \%$ effective supervision. However, for individuals who have time costs, especially those with high time costs, the current fines' binding force on them is open to question, or even invalid.

\section{Individuals' Waste Sorting Behavior Has High Cost, Low Utility and Low Willingness}

Before the implementation of the garbage classification management system in Shanghai, the cost for individuals to dispose of garbage was $c_{0}$. After the implementation of the garbage classification management system, the cost for individuals to dispose of garbage was $c_{0}+c_{1}$ for no time cost, and the cost for individuals to dispose of garbage with time cost was $c_{0}+c_{1}+$ opp The utility of the individuals to dispose of garbage before the garbage classification is $r-c_{0}$. After the implementation of the garbage classification management system, the utility of the individuals with no time cost to dispose of the garbage according to the regulations is $r-c_{0}-c_{1}$, and the utility of the individuals with the time cost to dispose of the garbage according to the regulations is $r-c_{0}-c_{1}-o p p$. Summary in Table 2.

It can be seen from Table 2 that under the premise of ensuring the effectiveness of the garbage classification management system, after the implementation of the garbage classification management system, the cost for individuals to dispose of garbage has increased, the benefits have not changed, and the utility has decreased. Individuals with time costs have a greater increase in cost and a greater decline in utility. The increase in

Table 2. The behavioral cost and utility of individuals' garbage disposal before and after the implementation of the garbage classification management system.

\begin{tabular}{|c|c|c|c|}
\hline Source Classification Behavior of Municipal Domestic Waste & Cost & Income & Utility \\
\hline $\begin{array}{c}\text { The behavior of all individuals handling garbage before the implementation } \\
\text { of the garbage classification management system }\end{array}$ & $c_{0}$ & $r$ & $r-c_{0}$ \\
\hline $\begin{array}{c}\text { Individuals' behavior of handling garbage without time cost after the } \\
\text { implementation of the garbage classification management system }\end{array}$ & $c_{0}+c_{1}$ & $r_{1}$ & $r-c_{0}-c_{1}$ \\
\hline $\begin{array}{c}\text { Individuals' behavior of handling garbage with time cost after the implementation } \\
\text { of the garbage classification management system }\end{array}$ & $c_{0}+c_{1}+o p p$ & $r_{2}$ & $r-c_{0}-c_{1}-$ opp \\
\hline
\end{tabular}

Note: $r-r_{1}-r_{2}$. 
Table 3. Statistics of violations of garbage disposal in Shanghai in July 2019.

\begin{tabular}{|c|c|c|}
\hline Violation ranking & Organization where the violation occurred & Violation rate \\
\hline 1 & Large shopping malls, commercial buildings & $50.9 \%$ \\
\hline 2 & Catering enterprises, enterprises and institutions & $26.5 \%$ \\
\hline 3 & Industrial parks, science and technology parks & $24.3 \%$ \\
\hline 4 & Hotels, inns & $23.4 \%$ \\
\hline 5 & Schools, residential areas, hospitals & $20 \%$ \\
\hline
\end{tabular}

Note: The data comes from the Shanghai Municipal Greening and City Appearance Bureau and the urban management department. ${ }^{1}$

behavioral costs and the decrease in behavioral utility are the fundamental reasons why individuals are unwilling to sort and dispose of garbage. Table 3 shows the statistics of illegal garbage disposal in Shanghai in July 2019. It can be seen from Table 3 that large shopping malls and commercial buildings have the highest incidence of violations, followed by catering companies, enterprises and institutions, the third is industrial parks and hotels, such as science and technology innovation, and the lowest is schools and residential communities and hospital. The garbage generated in large shopping malls and commercial buildings is solely borne by the enterprise. There are many types of garbage and many types of garbage, and the cost of garbage classification is high. Schools and residential communities have a small amount of garbage, and there are few types of garbage. Especially in residential communities, the garbage generated is borne by a single family, and the cost of garbage disposal is low. The incidence of violations is obviously positively correlated with the cost of behavior.

Increased costs and reduced utility have caused individuals to feel resistance to garbage classification, coupled with mismatched punishments, the probability of effective supervision is too low. If Shanghai's waste sorting management system is not adjusted, it is expected that the implementation effect will be greatly reduced and it will be difficult to last. Therefore, it is necessary to improve the existing waste sorting management system.

\section{Individuals' Behavior Analysis and Conceptual Model of Garbage Disposal under the "Dual Track" Garbage Classification Management System}

In view of the shortcomings of the current Shanghai garbage classification management system, it is necessary to improve the design of this system. The principle of improvement is to reduce the cost of supervision, reduce the cost of individuals' behavior, and improve the utility of individuals' behavior while

1 The data comes from the Shanghai Municipal Greening and
City Appearance Bureau in July 2019 . ensuring that the garbage classification management system is effectively implemented.

According to this principle, combining the characteristics of individuals with or without time cost, a waste sorting management system can be designed: Individuals who have the time cost purchase garbage sorting services from organizations such as "online hire workers" and community housekeeping attendants. Studies have shown that $69.2 \%$ of urban individuals in Jiangsu Province have the willingness to pay [54], assuming that the price of waste sorting service is less than or equal to the time cost $(g \leq o p p)$, and rewards will be given to individuals who have no time cost. For example, Fudan University introduced a smart recycling machine. 1000 grams of recyclables will earn 100 points, which is equivalent to 1 yuan, and you can withdraw them when you accumulate 20 yuan. This allows students to experience the convenience and benefits of garbage sorting, and the effect of garbage sorting for students is very obvious [55].

Under the premise of ensuring the effective implementation of the garbage classification management system, the cost of individuals' garbage disposal has been reduced, the utility of individuals' behavior has been improved, and Pareto improvements have been achieved. Fig. 4a) is a conceptual model of waste disposal for individuals with time costs under the "dual track system". a)

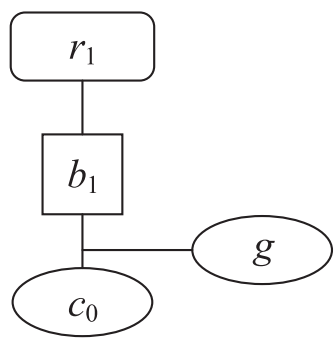

b)

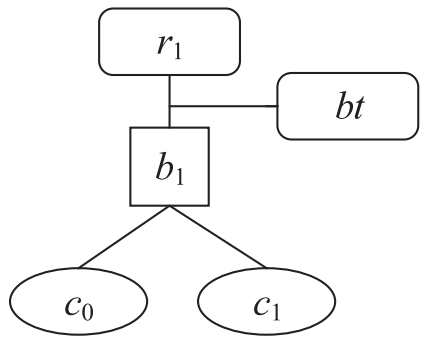

Fig. 4. a) A conceptual model of garbage disposal behavior in the "dual-track system" with time costs for individuals to purchase garbage sorting services; b) Conceptual model of individuals' garbage disposal as required by the "dual track system" without time cost. 
In Fig. 4a) g: The "dual track system" has a time cost for garbage classification service fees purchased by individuals.

Let the subsidy and reward for individuals without time cost be $b t, b t>0$. Fig. $4 \mathrm{~b}$ ) is a conceptual model of the "dual-track system" no-time cost individuals" behavior of handling garbage as required. Fig. 4b) is a conceptual model of the "dual-track system" notime cost individuals' behavior of handling garbage as required.

In Fig. 4b) bt: the subsidy or reward obtained after the implementation of the "dual track system" system, and the individuals who have no time cost to dispose of garbage as required. In the "dual-track" waste sorting management system, the conceptual model for individuals with time costs and individuals without time costs who fail to dispose of waste in accordance with regulations is the same as before the system design improvement.

Mathematical Model of Individuals' Garbage Disposal Behavior When Implementing the "Dual Track" Garbage Classification Management System

\section{Mathematical Model of Individuals' Waste Disposal Behavior without Time Cost}

- The mathematical model for individuals with no time cost to dispose of garbage according to regulations:

$$
u_{1}^{\prime \prime}=r_{1}-c_{0}-c_{1}+b t
$$

- The mathematical model of the individuals who do not have time cost to dispose of garbage according to regulations:

$$
u_{2}^{\prime \prime}=\left(1-p_{3}\right)\left(r_{2}-c_{0}\right)+p_{3}\left(r_{3}-c_{0}-c_{1}-s_{3}\right)
$$

Conditions for effective Garbage Classification Management System:

$$
u_{1}^{\prime \prime}>u_{2}^{\prime \prime}
$$

That is:

$r_{1}-c_{0}-c_{1}+b t>\left(1-p_{3}\right)\left(r_{2}-c_{0}\right)+p_{3}\left(r_{3}-c_{0}-c_{1}-s_{3}\right)$

In addition $r=r_{1}=r_{2}=r_{3}$.

Therefore, effective punishment $s_{3}{ }^{*}$ can be obtained:

$$
s_{3}^{*}>\frac{\left(1-p_{3}\right) c_{1}-b t}{p_{3}}
$$

Effective supervision probability $p_{3}{ }^{*}$.

$$
p_{3}^{*}>\frac{c_{1}-b t}{c_{1}+s_{3}}
$$

The amount of effective subsidies or rewards $b t^{*}$ :

$$
b t^{*}>\left(1-p_{3}\right) c_{1}-p_{3} \cdot s_{3}
$$

In other words, under the premise of ensuring the effectiveness of the system, the "dual-track" waste classification management system has a penalty of greater than $\left(\left(1-p_{3}\right) c_{1}-b t\right) / p_{3}$ for individuals who do not dispose of waste as required, or the probability of catching individuals who dispose of waste in violation of regulations is greater than $\left(1-p_{3}\right) c_{1}-b t>s_{3}$, or subsidies are greater than $\left(1-p_{3}\right) c_{1}-p_{3} \cdot s_{3}$.

\section{Mathematical Model of Garbage Disposal by Individuals with Time Cost}

- The mathematical model of garbage disposal behavior for individuals with time cost to purchase garbage sorting service:

$$
u_{1}^{\prime \prime \prime}=r_{1}-c_{0}-g
$$

...where $g<o p p$.

- Mathematical model of individuals who have time cost not disposing of garbage according to regulations:

$u_{2}^{\prime \prime \prime}=\left(1-p_{4}\right)\left(r_{2}-c_{0}\right)+p_{4}\left(r_{3}-c_{0}-c_{1}-o p p-s_{4}\right)$

Conditions for effective garbage classification management system:

$$
u_{1}^{\prime \prime \prime}>u_{2}^{\prime \prime \prime}
$$

That is:

$$
r_{1}-c_{0}-g>\left(1-p_{4}\right)\left(r_{2}-c_{0}\right)+p_{4}\left(r_{3}-c_{0}-c_{1}-o p p-s_{4}\right)
$$

Therefore, effective punishment $s_{4}{ }^{*}$ can be obtained:

$$
s_{4}^{*}>\frac{g-p c_{1}-p_{4} \cdot o p p}{p_{4}}
$$

Effective supervision probability $p_{4}{ }^{*}$ :

$$
p_{4}^{*}>\frac{g}{s_{4}+c_{1}+o p p}
$$

Purchase service fee for garbage sorting $g^{*}$ :

$$
g^{*}<p_{4}\left(s_{4}+c_{1}+o p p\right)
$$

In other words, the "dual-track" waste sorting management system, under the premise of ensuring the effectiveness of the system, will have a penalty of more 
than $\left(g-p_{4} c_{1}-p_{4} \cdot o p p\right) / p_{4}$ for individuals who do not follow the regulations to dispose of waste and have time costs, or the probability of catching individuals who dispose of garbage in violation of regulations is greater than $g /\left(s_{4}+c_{1}+o p p\right)$, or the purchased garbage sorting service fee is less than $p_{4}\left(s_{4}+c_{1}+o p p\right)$.

\section{Comparison of Current Management System and "Dual Track" Management System}

\section{Comparison of Punishment Intensity and Effective Supervision Probability}

Compare (5)(6)(14)(15) with (10)(11)(19)(20). For individuals with no time cost, because the subsidy is greater than zero $b t>0$, so $\left(1-p_{1}\right) c_{1} / p_{1}>\left(\left(1-p_{3}\right)\right.$ $\left.c_{1}-b t\right) / p_{3}$, that is $s_{1}>s_{3}$. Which shows that after the implementation of the "dual-track" management system, the requirements for penalties for violations have been reduced compared to the current management system, providing that the garbage classification system effectively implemented.

Similarly, because $b t>0$, so $c_{1} /\left(c_{1}+s_{1}\right)>\left(c_{1}-b t\right) /$ $\left(c_{1}+s_{3}\right)$, namely $p_{1}>p_{3}$. Which shows that after the implementation of the "dual-track" management system, the requirements for effective supervision probability have dropped under the condition that the garbage classification system is effectively implemented.

For individuals who have time costs, the cost of purchasing garbage sorting services is less than their time cost, otherwise they will choose to dispose of the garbage by themselves, that is $g<o p p$, so further $\left(1-p_{2}\right)\left(c_{1}+o p p\right)+p_{3}\left(c_{1}+o p p\right) />g$, it can be introduced $\left(1-p_{2}\right)\left(c_{1}+o p p\right)>g-p_{4}\left(c_{1}+o p p\right)$, that is $s_{2}>s_{4}$. Which shows that after the implementation of the "dual-track" management system, under the condition that the garbage classification system is effectively implemented, the requirements for penalties for violations have been reduced compared with the current management system.

Similarly, because $c_{1}+o p p>g$, so $\left(c_{1}+o p p\right)$ $/\left(c_{1}+o p p+s_{2}\right)>g /\left(c_{1}+o p p+s_{4}\right)$, namely $p_{2}>p_{4}$.
Which shows that after the implementation of the "dual-track" management system, the requirements for effective supervision probability have dropped under the condition that the garbage classification system is effectively implemented.

The above comparison can lead to the conclusion that the implementation of the "dual-track" garbage classification management system is better than the phenomenon of the phenomenon garbage classification management system. In real life, it means that the number of "police" can be reduced, and the government management cost is reduced.

\section{Comparison of Behavioral Utility}

Comparing equations (1)(2)(7)(12) and (17), it is found that whether they are individuals with no time cost or individuals with time cost, after the implementation of the "dual-track system", the behavioral effect of the garbage classification system is guaranteed. All have been improved, see Table 4 . In real life, it means that individuals' resistance to throwing garbage has decreased. For individuals who have no time cost, if the subsidy is greater than their garbage classification cost, the behavioral utility of the individuals' classification and disposal of garbage is higher than the behavioral utility of mixed garbage disposal. The act of sorting and disposing of garbage not only does not resist emotions, but is willing to accept such rules and regulations. For individuals with time costs, the service fee paid is less than the opportunity cost and sorting labor cost, and the utility is also improved.

In summary, under the condition of ensuring that garbage classification management is effectively implemented, the improved "dual-track" garbage classification management system has not only reduced the punishment, supervision and management costs, but also reduced the cost of individuals' garbage disposal and improved the effectiveness of individuals' garbage disposal. Thereby reducing individuals' resistance to garbage classification.

Table 4. Comparison of different garbage disposal behaviors.

\begin{tabular}{|c|c|c|c|}
\hline Different garbage disposal behaviors & Cost & Income & Utility \\
\hline Individuals' handling of garbage before garbage classification & $c_{0}$ & $r$ & $r-c_{0}$ \\
\hline $\begin{array}{l}\text { Individuals' garbage disposal behavior without time cost under the current management } \\
\text { system }\end{array}$ & $c_{0}+c_{1}$ & $r_{1}$ & $r-c_{0}-c_{1}$ \\
\hline $\begin{array}{l}\text { Individuals' garbage disposal behavior with time cost under the current management } \\
\text { system }\end{array}$ & $c_{0}+c_{1}+o p p$ & $r_{2}$ & $r-c_{0}-c_{1}-o p p$ \\
\hline $\begin{array}{c}\text { Individuals' garbage disposal behavior without time cost under the "dual track" } \\
\text { management system }\end{array}$ & $c_{0}+c_{1}$ & $r_{1}$ & $r-c_{0}-c_{1}+b t$ \\
\hline $\begin{array}{c}\text { Individuals with time-cost handling garbage disposal under the "dual track" management } \\
\text { system }\end{array}$ & $c_{0}+g$ & $r_{2}$ & $r-c_{0}-g$ \\
\hline
\end{tabular}

Note: $r=r_{1}=r_{2}, g<\left(o p p+c_{1}\right)$ 
The Connection Between the Third Party and the "Dual Track" Waste Classification Management System

The purchase of garbage classification services in the "dual track" garbage classification management system involves a third party. From the perspective of a rational person, buyers of garbage sorting services want quick service time and low charges. Among the thirdparty personnel, domestic servants, security personnel, and unemployed personnel in the same community who purchase garbage sorting services are all possible service providers. Especially domestic service staff, they help the garbage sorting buyers to dispose of the garbage when they dispose of their employer's garbage. At this time, the marginal cost of the domestic service staff is close to zero, but they have gained additional benefits, so the utility is positive. For waste sorting buyers, waste sorting labor and transportation labor are eliminated, and the service cost is between 0 and the time cost of waste buyers. If the price of housekeeping service personnel is too high, but is lower than the time cost of the garbage buyer, the garbage buyer may choose the "online hire" or other personnel's offer. Therefore, in order to exclude other competitors, the housekeeping service staff in the community must offer the lowest price among all competitors. In fact, the market mechanism and economic game in some communities in Shanghai has evolved part-time domestic service workers who sort waste. While serving employers, they charge RMB 300 a month for waste sorting purchasers in the community to obtain economic benefits. At the same time, it saves the time of individuals who have time costs, and the utility of both parties has been increased. The "dual-track" waste classification management system also involves subsidies or rewards for individuals who have no time costs. It can actively guide Internet companies such as Internet game companies, big data collection companies, and mobile companies to join. Since the marginal production costs of these companies' products are close to zero, subsidies or rewards for individuals without time costs will not incur substantial costs. Enterprises can obtain traffic import or government policy preferences, such as market access.

The improved "dual-track" waste sorting management system has reduced the cost of government supervision, increased the utility of individuals, increased the utility of waste sorting service providers, and increased the utility of waste sorting subsidies to reward providers, finally realizing Pareto improvement. Therefore, the design of the "dualtrack" waste classification management system is an effective management system that can achieve the goal of municipal solid waste source treatment.

\section{Conclusions and Policy Recommendations}

\author{
Conclusion
}

From the above research, it can be seen that the difficulty and pain point of municipal solid waste source classification behavior management is that individuals and other solid waste treatment actors are unwilling to classify the garbage, the behavior cost increases, the income remains unchanged, and the utility decreases because individuals are unwilling to choose to classify garbage. The fundamental reason, the key to governance is to reduce the behavioral cost of individuals' disposal of domestic waste and improve the utility. The effective implementation of the classification and treatment of urban domestic waste at the source not only requires strengthening supervision and penalties for violations, but also requires various measures to reduce the cost of individuals' garbage disposal, so that classification management policies can be effectively implemented and will not be abandoned halfway. Individuals who deal with garbage are divided into two types: timecost and non-time-cost. The waste sorting service fee is charged to individuals who have time cost, and the subsidy and reward is provided to individuals who do not have time cost. This can not only improve the effectiveness of individuals' garbage disposal, but also ensure the waste. Under the premise of effective implementation of classification, penalties for violations can be reduced, and government and social supervision costs can be reduced. The study also found that the current garbage classification management system implemented in Shanghai needs to be improved, and the system design and measures for the management of municipal solid waste source classification behaviors are insufficient. Including the mismatch of penalties, the low probability of effective supervision, the high cost and low utility of individuals' garbage disposal, the resistance of individuals and enterprises to the management of garbage classification, and the high incidence of violations. It is necessary to correct and improve these problems.

The research in this paper is based on mathematical deduction and demonstration based on pure theoretical assumptions. The advantage of the research method used is that even when there is no data and when it is difficult to quantitatively analyze variables, it can still mathematically model and derive economic management behavior, and obtain better qualitative conclusions. The disadvantage is that there is not enough data collected to verify and empirically analyze the research conclusions. In the future, when studying behavioral science issues including garbage classification, we will collect data as much as possible, conduct more in-depth empirical research, and further enhance the scientificity and practicality of the subject research. 


\section{Policy Recommendations}

Combining this article and foreign research results, it is recommended to add the following to the existing "Regulations of Shanghai Municipality on the Management of Domestic Waste".

\section{Adjusting Penalties for Violations}

In general, individuals with no time cost are more sensitive to economic punishment, and individuals with time cost are more sensitive to being included in the untrustworthy list. In addition to imposing financial penalties on the offenders, they must also be included in the list of dishonesty, and double punishment measures will be implemented [56]. The former has an obvious effect on individuals without time cost, and the latter has a strong deterrent effect on individuals with time cost. Punishment measures must not only become a system, but also be implemented, otherwise the system will fail. It can be short-term or long-term to be included in the untrustworthy list, and the judgment is based on the severity of the violation and the degree of repentance. If the first violation occurs, after being included in the short-term untrustworthy list, there is no second violation within one year, and the list is cancelled. If the violation occurs again within one year, it will be included in the long-term untrustworthy list.

\section{Improving the Probability of Effective Supervision}

The number of urban management personnel in major cities across the country, including Shanghai, is limited, making it difficult to effectively supervise the large number of individuals and organizations in the city. A series of measures such as the establishment of the "Whistle Blowing Act", installation of monitoring equipment, participation of public welfare organizations, development of Internet artificial intelligence technology, and encouragement of social groups such as retirees and students to participate, can increase the probability of effective supervision and reduce the cost of supervision [57]. A number of measures could be taken simultaneously to effectively curb the occurrence of illegal garbage disposal.

\section{Implementing a "Dual Track" Waste Classification Management System}

Two different sets of garbage classification management methods are implemented for individuals with no time cost and individuals with time cost. On the one hand, encourage the development of a garbage sorting service purchase market, establish a sound garbage sorting service purchase market mechanism, and use market methods to guide individuals who have time costs to purchase garbage sorting services from community security and housekeeping service personnel. On the other hand, the introduction of Internet companies, mobile communication companies and other institutions to implement subsidies and incentives for individuals who have no time cost [58], and cultivate their garbage classification habits.

The main contribution of this article is to use costutility theory to analyze the behavioral process of individuals handling domestic waste, and point out the fundamental reason why individuals are unwilling to choose waste classification. Based on practical considerations, the paper divides individuals into two types of groups with time cost and no time cost, and puts forward a "dual track" waste classification management strategy. The shortcomings of the thesis are that the punishment and the probability of effective supervision for the subjects of illegal garbage disposal are not given specific quantitative analysis because the data is difficult to obtain.

In short, the source classification management of municipal solid waste is a multi-disciplinary systematic project that integrates economics, management, systems, sociology, behavior, and Internet information technology. It is a long-term process and requires multiparty cooperation in society to be effectively solve.

\section{Ethical Statement}

This study did not require ethics approval as it is a systematic review that made use of existing primary studies that have been published in peer-reviewed academic journals. It did not involve human or animal participants, material, or data.

\section{Financial Support}

This research did not receive any specific grant from funding agencies in the public, commercial, or not-forprofit sectors.

\section{Conflict of Interest}

The authors declare no conflict of interest.

\section{References}

1. DONG F., YU B.L., PAN Y.L. Examining the synergistic effect of $\mathrm{CO}_{2}$ emissions on PM2.5 emissions reduction: Evidence from China. Journal of Cleaner Production, 223 (20), 759, 2019.

2. LIU Y.J., DONG F. Haze pollution and corruption: A perspective of mediating and moderating roles. Journal of Cleaner Production, 279, 123550, 2021.

3. FAN W.Y., XUE L.Q. Why did the previous classifications of domestic waste have little effect - and on the system construction in the era of compulsory classification. Exploration and Contending, 358 (08), 150, 2019. 
4. MENG X.Y., WEN Z.G., QIAN Y. Multi-agent based simulation for household solid waste recycling behavior. Resources, Conservation and Recycling, 28 (01), 535, 2018.

5. ZHAO Q. The new trend of waste sorting and management in Beijing communities: taking the community of No.1 Xinfeng street as an example. Energy Conservation, $\mathbf{3 8}$ (09), 146, 2019.

6. RAO L.L., ZHENG D.Y. A comparative study on the classification and treatment of domestic waste in Tokyo, Japan and Beijing, China. Journal of Kaifeng Institute of Education, 36 (08), 289, 2016.

7. MENG X., TAN X., WANG Y., et al. Investigation on decision-making mechanism of residents' household solid waste classification and recycling behaviors. Resources, Conservation and Recycling, 140, 224, 2019.

8. SUN X., ZHANG S., HAN B. On the implementation of smart waste sorting terminals and models in China. Environmental Protection, 47 (12), 21, 2019.

9. HOWAT A.J. The role of value perceptions in intergroup conflict and cooperation. Politics Groups and Identities, 21, 1, 2019.

10. WHITEMAN R.C., MANGELS J.A. State and trait rumination effects on overt attention to reminders of errors in a challenging general knowledge retrieval task. Frontiers in Psychology, 11, 2094, 2020.

11. RAMACHANDRA T.V., BHARATH H.A., KULKARNI G., HAN S.S. Municipal solid waste: generation, composition and GHG emissions in Bangalore, India. Renewable and Sustainable Energy Reviews, 82, 1122, 2018.

12. PINTO S., et al. Evolutionary analysis of the concept of comfort. Holistic Nursing Practice, 31 (4), 243, 2017.

13. CHOE J.Y., KIM J.J., HWANG J. The environmentally friendly role of edible insect restaurants in the tourism industry: applying an extended theory of planned behavior. International Journal of Contemporary Hospitality Management, 32 (11), 3581, 2020.

14. OYEKALE A.S. Determinants of households' involvement in waste separation and collection for recycling in South Africa. Environment Development and Sustainability, 20 (5), 2343, 2018.

15. KLEINHANS K., HALLEMANS M., HUYSVELD S., et al. Development and application of a predictive modelling approach for household packaging waste flows in sorting facilities. Waste Management, 120, 290, 2021.

16. ZHAO L., DETLOR B. Towards a contingency model of knowledge sharing: interaction between social capital and social exchange theories. Knowledge Management Research \& Practice, 1-13, 2021.

17. AZEVEDO B., SCAVARDA L., CAIADO R., et al. Improving urban household solid waste management in developing countries based on the German experience. Waste Management, 120, 772, 2021.

18. WANG H., MA Y., YANG S., KOONDHAR M., KONG R. The spillover influence of household waste sorting on green consumption behavior by mediation of environmental concern: evidence from rural China. International Journal of Environmental Research and Public Health, 17 (23), 9110, 2020.

19. ABELIOTIS K., LASARIDI K., CHRONI C. Food waste prevention in Athens, Greece: the effect of family characteristics. Waste Management \& Research, 34 (12), 1210, 2016.

20. ANDREWS L., KERR G., PEARSON D., MIROSA M. The attributes of leftovers and higher-order personal values. British Food Journal, 120 (9), 1965, 2018.
21. ASCHEMANN-WITZEL J., DE-HOOGE I., et al. Consumerrelated food waste: causes and potential for action. Sustainability, 7 (6), 6457, 2015.

22. BIRAU M.M., FAURE C. It is easy to do the right thing: avoiding the backfiring effects of advertisements that blame consumers for waste. Journal of Business Research, 87, 102, 2018.

23. LV W.X., WANG C.J. Research on mobilization methods, environmental awareness and residents' waste classification behaviors - an empirical study based on causal intermediary analysis. Journal of China University of Geosciences (Social Sciences Edition), 20 (02), 103, 2020.

24. XU L., LING M.L. Analysis of the spillover effect of residents' waste classification behavior intervention policy - a field quasi-experimental study. Zhejiang Social Sciences, 11, 65, 2019.

25. ZHANG H., LIU J., WEN Z.G., et al. College students' municipal solid waste source separation behavior and its influential factors: a case study in Beijing, China. Journal of Cleaner Production, 164, 444, 2017.

26. YAN Y.J., YAN Y.L. Discussion on the implementation problems and countermeasures of the pilot policy of municipal solid waste classification - taking Meilong San village, Xuhui district, Shanghai as an example. Ecological Economy, 36 (03), 197, 2020.

27. ZHU Q., ZHANG W., LUO Z.H. Sequential decision analysis of multiple subjects of municipal solid waste classification from the perspective of producer responsibility. Enterprise Economics, 02, 24, 2020.

28. RAZALI F., DAUD D., WENG-WAI C., et al. Waste separation at source behaviour among Malaysian households: The Theory of Planned Behaviour with moral norm. Journal of Cleaner Production, 271, 122025, 2020.

29. MOUSAVI S.A., KHASHIJ M., SALMANI M. Knowledge, attitude and practices concerning municipal solid waste recycling among the people in Gilangharb, Iran. International Research Journal of Applied and Basic Sciences, 10 (2), 135, 2016.

30. DI TALIA E., SIMEONE M., SCARPATO D. Consumer behaviour types in household food waste. Journal of Cleaner Production, 214 (MAR.20), 166, 2019.

31. DOORN J.V. Commentary: why do we waste so much food? a research agenda. Journal of the Association for Consumer Research, 1 (1), 53, 2016.

32. ELLISON B., LUSK J.L. Examining household food waste decisions: a vignette approach. Applied Economic Perspectives and Policy, 40 (4), 613, 2018.

33. GIORDANO C., ALBONI F., CICATIELLO C., FALASCONI L. Do discounted food products end up in the bin? an investigation into the link between deal-prone shopping behaviour and quantities of household food waste. International Journal of Consumer Studies, 43 (2), 199, 2019.

34. GOJARD S., VERON B. Shopping and cooking: the organization of food practices, at the crossing of access to food stores and household properties in France. Review of Agricultural, Food and Environmental Studies, 99 (1), 97, 2018.

35. WANG L.P. Analysis of consumer attitudes and influencing factors of environmentally friendly products - based on the investigation of community residents in Jiaozuo city. Arid Land Resources and Environment, 30 (02), 7, 2016.

36. GRAHAM-ROWE E., JESSOP D.C., SPARKS P. Selfaffirmation theory and pro-environmental behaviour: 
promoting a reduction in household food waste. Journal of Environmental Psychology, 62, 124, 2019.

37. HEBROK M., HEIDENSTROM N. Contextualising food waste prevention - decisive moments within everyday practices. Journal of Cleaner Production, 210 (FEB.10), 1435, 2019.

38. MENG X.Y., WEN Z.G., QIAN Y. Multi-agent based simulation for household solid waste recycling behavior. Resources, Conservation and Recycling, 128, 535, 2018.

39. LOU M. Study on the influencing factors of the source classification of urban waste - taking the inner district of Tianjin as an example. Arid Land Resources and Environment, 34 (04), 15, 2020.

40. KOWALEWSKA M.T., KOLLAJTIS-DOLOWY A. Food, nutrient, and energy waste among school students. British Food Journal, 120 (8), 1807, 2018.

41. NIKOLAUS C.J., NICKOLS-RICHARDSON S.M., ELLISON B. Wasted food: a qualitative study of U.S. young adults' perceptions, beliefs and behaviors. Appetite, 130, 70, 2018.

42. CHEN F.Y. Research on driving mechanism and policy simulation of urban residents' waste classification behavior. China University of Mining and Technology, 27, 2018.

43. REVILLA B.P., SALET W. The social meaning and function of household food rituals in preventing food waste. Journal of Cleaner Production, 198, 320, 2018.

44. YUAN Y., NOMURA H., TAKAHASHI Y., et al. Model of Chinese household kitchen waste separation behavior: a case study in Beijing city. Sustainability, 8 (10), 1, 2016.

45. PIRAS S.P., PANCOTTO F., RIGHI S., et al. Community social capital and status: The social dilemma of food waste. Ecological Economics, 183, 106954, 2021.

46. LIU C.L., LIU M.M. Analysis on the path of rural domestic waste governance from the perspective of social capital theory. Journal of Beijing University of Chemical Technology (Social Science Edition), 04, 32, 2020.

47. HUA Y.F., DONG F., GOODMAN J. How to leverage the role of social capital in pro-environmental behavior: A case study of residents' express waste recycling behavior in China. Journal of Cleaner Production. 280 (02), 124376, 2021.
48. SOSNA D., BRUNCLIKOVA L., GALETA P. Rescuing things: food waste in the rural environment in the Czech Republic. Journal of Cleaner Production, 214, 319, 2019.

49. LI C.A., GUO J.H, CHEN Q.Q., HU C.P. Research on the differentiated participation mechanism of residents in the classification and recycling of domestic waste - based on the comparison of pilot and non-pilot communities in Hangzhou. Arid Land Resources and Environment, 32 (08), 23, 2018.

50. CARMO S.I.D., DUTRA D.B.M. Drivers and barriers to food waste reduction. British Food Journal, 120 (10), 2364, 2018.

51. YOUNG W., RUSSELL S., ROBINSON C., CHINTAKAYALA P. Sustainable retailing - influencing consumer behaviour on food waste. Business Strategy and the Environment, 27 (1), 1, 2018.

52. BOONROD K., TOWPRAYOON S., BONNET S., et al. Enhancing organic waste separation at the source behavior: a case study of the application of motivation mechanisms in communities in Thailand. Resources, Conservation \& Recycling, 95, 77, 2015.

53. SUN S.R. The Science of Institutional Design-Institutional Engineering, 1rd ed.; Publisher: Science and Technology Press, China, 1, 2018 [In Chinese].

54. JIA W.L. Research on residents' willingness to pay and influencing factors for the classification and treatment of municipal solid waste - based on the empirical analysis of Jiangsu province. Arid Land Resources and Environment, 34 (04), 8, 2020.

55. ZHANG H.H. Rethinking and optimization of ecological civilization education- speaking from waste classification. Ideological and Theoretical Education, 10, 107, 2019.

56. DONG F., YU B.L., PAN Y.L. Examining the synergistic effect of $\mathrm{CO}_{2}$ emissions on $\mathrm{PM}_{25}$ emissions reduction: Evidence from China. Journal of Cleaner Production, 223, 759, 2019.

57. DONG F., LIU Y.J. Policy evolution and effect evaluation of new-energy vehicle industry in China. Resources Policy, 67, 101655, 2020.

58. YANG X., WANG M., HU Q. Garbage classification: action dilemma, governance logic and policy path. Governance Research, 35 (06), 108, 2019. 